\title{
Interpretation Strategies and Interpretation Performance in Interlingual and Bilingual Subtitling: A Case of Iranian BA Translation Students
}

\author{
Ghasem Modarresi ${ }^{1}$, Kaveh Jalilzadeh ${ }^{2} \&$ Raheleh Zolfaghary ${ }^{3}$ \\ ${ }^{1,3}$ Department of English, Quchan Branch, Islamic Azad University, Quchan, Iran \\ ${ }^{2}$ Department of Foreign Languages, Istanbul University-Cerrahpassa, Turkey \\ qasem.modarresi@gmail.com
}

\begin{abstract}
ARTICLE HISTORY
Received : 2020-11-27

Revised :2020-12-05

Accepted : 2020-12-24
\end{abstract}

\section{KEYWORDS}

Interlingual subtitling

Bilingual subtitling

Interpretation performance

\begin{abstract}
The researchers in Interpreting Studies have underrated the importance of interpretation strategies in interpretation courses at the university level in the Iranian context. As a mixed-method study, the present study mainly aimed at discovering the subtitling strategies used in interlingual subtitling and bilingual subtitling by translation students. The researchers selected 30 homogeneous students majoring in Translation Studies which were divided into two experimental groups. During the treatment phase, the researchers worked with each group's students on subtitling strategies on a comedy film, following Peterson's (2005) strategies. The results of the post-tests confirmed that there was a significant difference for interlingual subtitling since the students' scores increased significantly from the mean score of 24.53 to the mean score of 27.66 as well as for bilingual subtitling since the students' scores increased significantly from the mean score of 22.80 to the mean score of 27.13. However, the results revealed no significant difference in students' interpretation scores for interlingual and bilingual subjects. The results of the interviews also supported the effectiveness of audio-visual activities on oral translation. Translation students should pay attention to how they foster their interpreting competence and find the type of subtitling that is more beneficial.
\end{abstract}

\section{Introduction}

Subtitling occupies an absolute position in the target culture (Karamintroglou, 1999). The researchers cannot either ignore or underestimate the role of this kind of translation in the target culture, especially our culture. Not noticeable numbers of research works have been dedicated to this area of study because it is a widespread phenomenon which involves the whole world during the last two decades (Gottlieb, 1992). Subtitling is, indeed, accounted for different with literal written ones. Subsequently, it can be claimed that this area of study occupies the primary position in our country and many other countries. It will be more common and crucial in target cultures and translation studies as media blockbusters, especially movies, continue to seize the mind of those cultures' people and even control their daily reactions.

Among the various types of screen translation, subtitling has become increasingly necessary because of several factors. First, the rising demand for international TV programs to feed the accelerating number of television channels has led to a growing interest in subtitling as a relatively cheap way of translating audio-visual languages (O'Connell, 2007). In addition, the demand for authenticity among audiences is increasing, with a greater awareness of foreign languages in general and in particular the English language (Szarkowska, 2005). In several countries subtitles are also used to revive and teach minority languages, boost the literacy of the mother tongue, teach immigrant groups the official language of a nation, and encourage foreign language skills. Another pattern for many countries is the rise in the replacements of TV programs to the deaf and hard of hearing (O'Connell, 2007). The correct translation of the original messages is essential in subtitling since hasty translation can misunderstand it (Jalilzadeh, Modarresi, \& Rohani, 2020). Indeed, the use of strategies in subtitling can yield a better translation. For example, the study conducted by Khakshour Forutan and Modarresi (2018) showed that the most applied strategies in the subtitled version were Substitution, Cultural and Direct Translation while the most applied strategy in the dubbed version was an omission.

The study's significance lies in the fact that it is possible to offer better, more comprehensible and more loyal translation through an in-depth perception of strategies used in interpretation. When we consider translation students' interpretation performance, we can improve future works' quality and identify the common mistakes and strategies committed and happened in their performance to avoid incorrect and inappropriate cases. Today, one of the most critical research areas in interpretation studies concerns attempts to incorporate psychological trends into teaching and learning interpretation. For example, 
Modarresi (2019) showed that getting involved in translation tasks activates cognitive processes. Davies (2004) remarked in teaching translation, specific needs, context information, personality and learning styles of students should be considered for the development of pedagogical resource and technique to enhance students' translation skills and results.

The major problem encountered by trainers working with the translation students on films and news taken from English-speaking countries is that they expose students to the films. The students become frustrated since they cannot understand the message because of a lack of vocabulary knowledge fast speech. The previous research on subtitling has not focused on comparing different subtitling types, and they look at subtitling as a unitary concept. However, investigating different types of subtitling is what the current study mainly pursue. An important research domain in interpretation is the number of exposure students could have in interpretation training courses. Indeed, it works on the original films accompanied by subtitles have always been an effective strategy in such courses. The teachers and researchers have different perspectives on the use of subtitling types and techniques in this regard.

The study mainly tried to compare the interpretation strategies that are used in interlingual subtitling and bilingual subtitling. Interlingual subtitling is between two languages. This type is "diagonal, in the sense that the subtitler crosses over from speech in one language to writing in another, thus changing mode and language" (Gottlieb, 1998, p. 32). Bilingual subtitling refers to where subtitles "are provided simultaneously in two languages" (Gambier, 2003, p. 12). The researchers believe that subtitling types may influence the translators' strategies while working on this aspect of subtitling can contribute to the betterment of subtitling, enhancing students' performance in interpretation courses. When reading speed and the rate of structured presentation, it is difficult to generalize. According to Luyken et al. (1991), adult viewers' reading speed hovers around 150 to 180 words per minute. However, the complexity of the linguistic and factual details found in the subtitles depends on extensive variation. When the lexical density is high, information usability appears to be low, requiring additional subtitles of exposure time. Moreover, readability is said to be influences by genre of film.

\subsection{Interpretation: An Overview}

Nearly for the last fifteen years, interpretation has deeply determined itself as a complete profession separate from translation (Darwish, 2003). Darwish (2003) stated, "despite being older than translation, interpreting has always been somewhat confused with translation, and interpreters have for a long time lived in the shadows of translators" (p. 1). It has elaborated during this century. Consecutive and simultaneous are various types of interpretation that can be considered a stressful profession (Mendez, 2001). As-Safi (2001) defines interpretation similarly as "Interpreting comprises in conveying to the target language the most accurate, natural equivalent of the source language oral message" (p. 12). The article was written in the official publications of the European communities also defines interpretation as Spoken versions offered by interpreters that express, in other words, the content and meanings of the statements by the original speaker.

Interpreting is divided into two main major modes: Consecutive interpreting and simultaneous interpreting. In Consecutive Interpreting (CI), The interpreter listens for a few minutes to a speech section, takes notes, and then delivers the whole segment in the target language. "A few minutes the speaker returns, the translator delivers the next section and the process continues until the end of the speech" (Gile, 1995, p. 42). Simultaneous interpreting is often referred to as listening and speaking concurrently' or 'holding the spoken message while simultaneously formulating and articulating the translated message (Mizuno, 2005). According to Hulme (2000), simultaneous interpreting amounts almost precisely to what is referred to as articulatory suppression in studies of short-term memory. Simultaneous interpreting is a demanding and complex task that uses the working memory to its extreme (Osaka, 2002). The literature shows that interpreting interpretation is not easy and needs quantitative rubrics (Khoramy \& Modarresi, 2019).

\subsection{Subtitling and Interpretation}

Subtitling has been used since 1929 when the first talkies reached Europe (Baker, 1998). Subtitles evolved out of the intertitles used as devices to convey the actors' dialogue to the audience. Karamitroglou (1999) conducted a study on subtitling types and found that intertitle could be a replacement shot for a part of a film that contained verbal information in the original language. Bot (2005) carried out a study on subtitling, and in his study, he stated that texts were printed on cardboards and were later filmed and inserted between sequences of the film. It seems that the invention of talking films in 1927 led to the gradual disappearance of intertitles, and the problem of language transfer took on new dimensions; as a result, dubbing was born. However, subtitling as a cheaper method of language transfer developed further. The technique of inserting subtitles onto the film was improved over the years.

\subsection{Theoretical Framework of the Study}

The study followed the theoretical framework suggested by Gambier (2003), who classified different types of audio-visual activity including 1) interlingual subtitling, where subtitles are provided in the target language, 2) bilingual subtitling, where subtitles are provided simultaneously in two languages, 3) intralingual subtitling for the hard of hearing, increasingly a regulatory requirement, 4) dubbing, which covers 'lip-synchronization' or 'lip-sync', where 
a TL voice-track, 5 replace the SL voice track) voiceover, used mainly for documentary or interview, 6) subtitling, subtitles projected above the stage or on the seatbacks at the opera or theatre, 7) audio description, and a mainly intralingual audio commentary the action on the stage or film for the visually impaired. The present study selected two of these audio-visual activities, including the first and second ones, which were the most critical audio-visual activities.

The researchers posed four questions to carry out the present study, including:

a) Does instructing Pedersen's (2005) strategies affect BA translation students' oral translation using interlingual subtitling?

b) Does instructing Pedersen's (2005) strategies affect BA translation students' oral translation through bilingual subtitling?

c) Is there any significant difference between BA translation students' oral translation by means of interlingual and bilingual subtitling?

d) What do the students think about the influence of types of audio-visual activity on their oral translation performance?

\section{Method}

The present study used a mixed-method study using a quantitative experimental study complemented with the qualitative interview method to yield more in-depth findings.

\subsection{Participants/corpus}

The researchers selected 30 students (both male and female students) majoring in Translation Studies participated in this study from the Tabaran University of Mashhad and the Imam Reza University of Mashhad. The reason for selecting the students from two universities was the few translation students in each university. The students studied Interpretation Two as a two-credit course, and they already had passed their Interpretation One. The researchers selected interpretation two since they had already experienced the course, and all are nearly at the same level of proficiency. The students were in their semester five or six. Their language proficiency level was assessed through Preliminary English Test (PET) including listening skills. Therefore, given one standard deviation above and below the mean, students whose scores obtained from PET were between 16 and 12 were selected to participate in the study (since $14+2=16$ and $14-2=12$ ). Therefore, out of 40 students, 30 students were remained to participate in the study. Having selected students at the same level of language proficiency, the researchers started his research work. Moreover, four of the students were interviewed after the treatment based on availability sampling. As the study's corpus, the researchers employed a comedy movie named "Good Kids" directed by Chris McCoy (2016) to be worked in the treatment phase in both groups. The reason for selecting this film was the genre of the films, which was a comedy and the language level of the film was not so difficult for the students.

\subsection{Instrumentations}

As the first instrument of the study, the researchers used the Preliminary English Test (PET). PET developed by Cambridge ESOL, is part of a group of examinations called the Cambridge Main Suite, and it is equivalence with English qualification B1. The test includes three main sections: Reading/Writing, Listening and Speaking. The listening part consists of 4 parts ranging from short exchanges to more extended dialogues and monologues. The listening section's objective was to assess candidates' ability to understand dialogues and monologues in both informal and neutral settings on a range of everyday topics. The listening part included 25 items and lasts 35 minutes. Based on the measurement scales proposed by PET, each item carries one mark, which gives a total of 25 marks.

The second instrument was the pre-test taken from the original films in the English language appropriate for intermediate English learners. The third instrument was the post-test taken from the same film used in the pre-test. The pre-test and post-test difficulty levels were approximately the same, and each clip had about five minutes long.

For the fourth instrument of the study, to assess students' performance on interpretation, the researchers utilized Wu's (2010) Interpretation Assessment Criteria as a comprehensive, objective assessment in this regard. There are five primary criteria in this rubric including 1) Presentation and Delivery, 2) Fidelity and Completeness, 3) Audience Point of View, 4) Interpreting Skills and Strategies and 5) Foundation Abilities for Interpreting. Each of these categories consists of sub-categories, as evident in the framework. The primary reason that the researchers selected the rubrics was that it could match the four basic constructs that a good interpreter requires, including language competence, interpreting skills, background knowledge, and personal aptitude. This questionnaire's scoring procedure is between 12 and 48 since there are 12 properties, and for each one, the maximum and minimum scores are 4 and 1 , respectively.

The study's last instrument was semi-structured questions, requiring the participants to reveal their views of the influence of training interpretation strategies on their performance on interpretation courses. Two experts in translation who had been teaching translation courses at the Ferdowsi University of Mashhad and the Islamic Azad University of Quchan checked the questions' content validity. The researchers, having received the experts' feedback, revised the questions in terms of their validity. The study's findings from the interviews also showed that the question items possessed dependability since the finding revealed consistency. 


\subsection{Procedure}

The researchers decided to undertake the study during the class hour by the prior agreement with the instructor at Tabaran University and the Imam Reza University of Mashhad. During the first session, they distributed the PET to students, and the data were gathered. The treatment phase was planned to last for one term. There were two experimental groups in this study; one group was provided by interlingual subtitling, and the other group was provided by bilingual subtitling during the course. Thus, the present study was experimental.

Regarding the assessment of students' interpretation performance in their pre-test and post-test performance, participants were provided sufficient and clear instructions in advance as to how to carry the task of interpreting. It was particularly crucial before the pretest, for very few subjects were expected to try such a task previously. The video clip for pre-test and posttest were played on a Video Projector, and participants listened to it through a good quality and translated it in front of two raters. The students were asked to come to the class two by two, and the two raters assessed their performance on interpretation. In this way, the researchers took care of inter-rater reliability of scores using the rubrics suggested by $\mathrm{Wu}$ (2010) for measuring the students' performance.

During the treatment phase, the researchers worked with each group's students on subtitling strategies following Peterson (2005). They examined the subtitling in terms of the four strategies including 1) Official Equivalent based on which ST equivalence has already been established in TL, 2) Specification-based on which the ST element is retained in its untranslated form and instead more information is added to clarify the meaning, 3) Substitution based on which ST word replaced with something else, and finally, 4) Omission based on which ST word is removed, bringing nothing as its substitution. The teacher worked on the strategies through interlingual subtitling and bilingual subtitling and tried to see which of the subtitling types help students improve their interpretation performance.

Finally, the students were interviewed based on availability sampling from the two groups. The Persian Language questions were written to gather the participants' responses to the effectiveness of subtitling types. The students were required to reply to the Persian Language questions since using their native language could express themselves more quickly and precisely. Their writings were, then, translated into English, analyzed, and categorized. The writing task resembled a semi-structured interview, in which subjects could express their thinking with very little interference. The pupils had approximately ten minutes to talk about their perspectives.

\section{Findings}

\subsection{Interlingual Subtitling and Interpretation}

As for the first research hypothesis concerning the effect of instructing Pedersen's (2005) strategies on BA translation students' interpretation employing interlingual subtitling, the researchers opted for Paired Sample t-test. Two raters measured the students' scores on the pre-test and post-test of interpretation out of 48 based on $\mathrm{Wu}$ (2010) assessment rubrics for interpreting. The correlation coefficient between the two raters' scores was .52 and .76 for the pre-test and post-test scores that were acceptable. The results of Descriptive Statistics are first reported:

Table 3.1 Descriptive statistics for interlingual subtitling

\begin{tabular}{llllll}
\hline \hline & & Mean & $\mathrm{N}$ & Std. Deviation & Std. Error Mean \\
\hline Pair 1 & pre-test & 24.53 & 15 & 3.02 & .77 \\
& post-test & 27.66 & 15 & 4.20 & 1.08 \\
& & & & \\
\hline \hline
\end{tabular}

As displayed by Table 3.1, the results revealed that the mean score for students' performance on the pretest was 24.53 with the standard deviation of 3.02, and the mean score for students' performance on the post- test was 27.66 with the standard deviation of 4.20. Following this, the results of Paired Sample t-test are reported below:

Table 3.2 Paired Samples test for interlingual subtitling

\begin{tabular}{|c|c|c|c|c|c|c|c|c|}
\hline & \multicolumn{5}{|c|}{ Paired Differences } & \multirow[b]{3}{*}{$\mathrm{t}$} & \multirow[b]{3}{*}{$\mathrm{df}$} & \multirow{3}{*}{$\begin{array}{l}\text { Sig. }(2- \\
\text { tailed) }\end{array}$} \\
\hline & \multirow[b]{2}{*}{ Mean } & \multirow{2}{*}{$\begin{array}{c}\text { Std. } \\
\text { Deviation }\end{array}$} & \multirow{2}{*}{$\begin{array}{l}\text { Std. Error } \\
\text { Mean }\end{array}$} & \multicolumn{2}{|c|}{$\begin{array}{l}\text { 95\% Confidence Interval of } \\
\text { the Difference }\end{array}$} & & & \\
\hline & & & & Lower & Upper & & & \\
\hline $\begin{array}{l}\text { Pair } 1 \text { pre-test interlingual - } \\
\text { post-test interlingual }\end{array}$ & -3.13 & 3.11 & .80 & -4.85 & -1.40 & -3.89 & 14 & .002 \\
\hline
\end{tabular}


To figure out if there is a significant difference between the pre-test and post-test scores for interlingual subtitling, having checked the column labelled Sig. (2-tailed) Table 3.2 revealed a significant difference in the mean scores on the dependent variable for each of the two sets of scores. Because of the value in the Sig. (2-tailed) the column is less than .05 (which is .002), there is $a$ significant difference between the two sets of scores. Since the mean scores of students following the treatment $(M=27.66)$ were more than their mean scores before the treatment $(M=24.53)$, it was concluded that the students improved in their interpretation scores. The researchers used eta squared to determine the instruction's effect size, as the most commonly used formula: $\mathrm{t} 2 / \mathrm{t} 2+(\mathrm{N}-1)$. As Table 2 shows, in this study, $\mathrm{t}=-3.89$. Therefore: $(-3.89)^{2} /(-$ $3.89)^{2}+(15-1)=15.13 / 29.13=0.51$. The guidelines (proposed by Cohen, 1992) for interpreting this value are: $.01=$ small effect, $.06=$ moderate effect, . $14=$ large effect. Therefore, the effect size of .51 is large. That is, intervention in the interlingual group had a large effect on the students' interpretation performance.

During the treatment phase, the researchers worked with the students on the strategies used in subtitling following the guidelines suggested by Pedersen's (2005) strategies, including official translation, specification, substitution and omission. Some samples are presented below based on the strategies extracted from the films worked in the class.

Table 3.3 Interlingual Subtitling: Specification

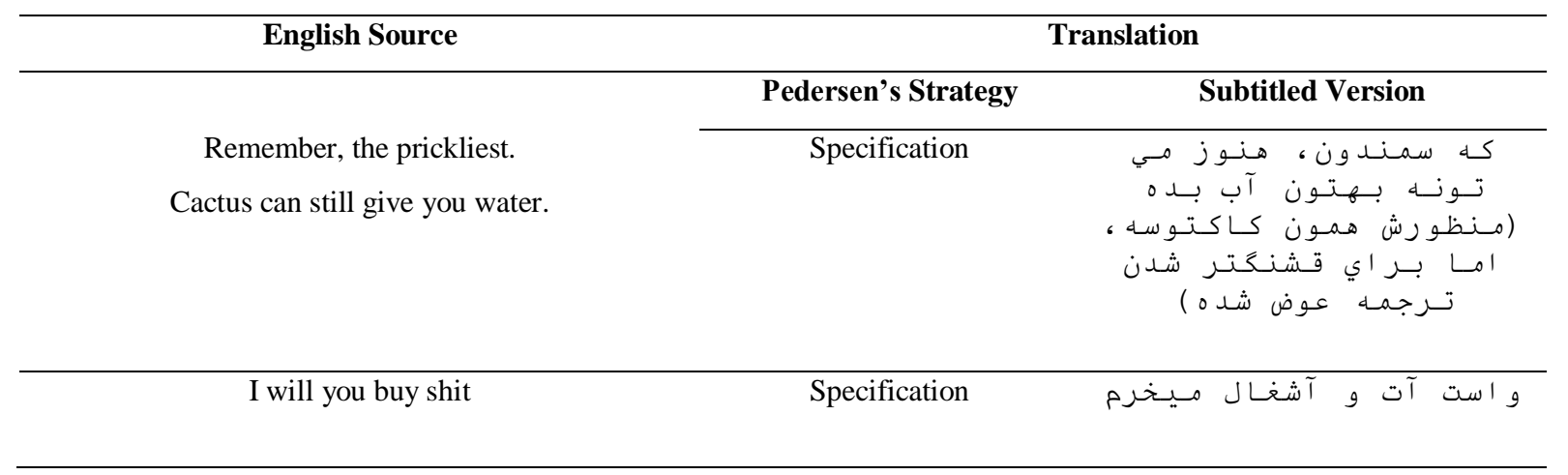

Table 3.4 Interlingual Subtitling: Substitution

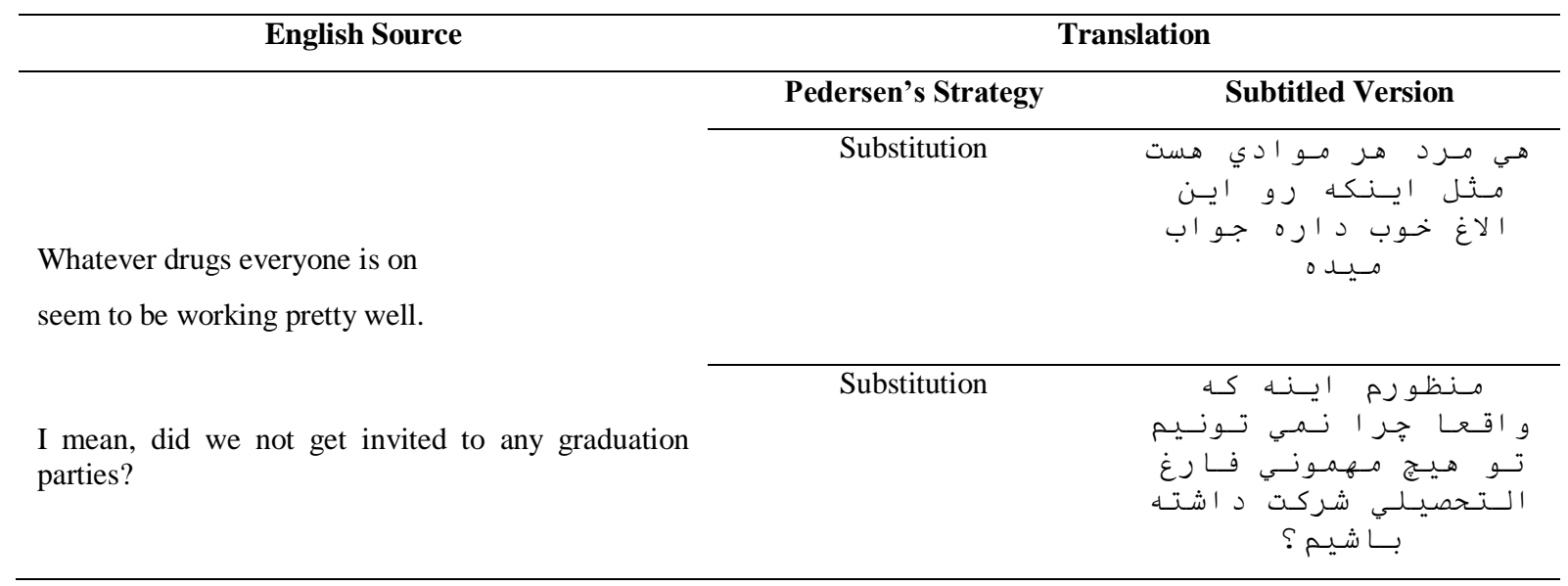

\subsection{Bilingual Subtitling and interpretation}

The second research hypothesis concerning the effect of instructing Pedersen's (2005) strategies on BA translation students' interpretation using bilingual subtitling, the researchers opted for Paired Sample ttest. Two raters measured the students' scores on the pre-test and post-test of interpretation out of 48 based on $\mathrm{Wu}$ (2010) assessment rubrics for interpreting. The correlation coefficient between the two raters' scores was .68 and .59 for the pre-test and post-test scores that were acceptable. The results of Descriptive Statistics are first reported: 
Table 3.5 Descriptive statistics for bilingual subtitling

\begin{tabular}{llcclc}
\hline \hline & & Mean & $\mathrm{N}$ & Std. Deviation & Std. Error Mean \\
\hline Pair 1 & pre-test & 22.80 & 15 & 2.56 & .66 \\
& post-test & 27.13 & 15 & 2.69 & .69 \\
& & & & \\
\hline \hline
\end{tabular}

As shown in Table 3.5, the results revealed that the mean score for students' performance on the pre-test was 22.80 with the standard deviation of 2.56 , and the mean score for students' performance on the post-test was 27.13 with the standard deviation of 2.69 . Following this, the results of Paired Sample t-test are reported below:

Table 3.6 Paired samples test for bilingual subtitling

\begin{tabular}{|c|c|c|c|c|c|c|c|c|}
\hline & \multicolumn{6}{|c|}{ Paired Differences } & \multirow[b]{3}{*}{ df } & $\begin{array}{l}\text { Sig. } \\
\text { tailed })\end{array}$ \\
\hline & \multirow[b]{2}{*}{ Mean } & \multirow[b]{2}{*}{$\begin{array}{l}\text { Std. } \\
\text { Deviation }\end{array}$} & \multirow[b]{2}{*}{$\begin{array}{l}\text { Std. } \\
\text { Mean }\end{array}$} & \multicolumn{3}{|c|}{$\begin{array}{l}\text { 95\% Confidence Interval of } \\
\text { the Difference }\end{array}$} & & \\
\hline & & & & Error_ & Upper & t & & \\
\hline $\begin{array}{l}\text { Pair } 1 \text { pre-test bilingual } \\
\text { post-test bilingual }\end{array}$ & --4.33 & 3.22 & .83 & -6.11 & -2.54 & -5.20 & 14 & .000 \\
\hline
\end{tabular}

To figure out if there is a significant difference between the pre-test and post-test scores for bilingual subtitling, having checked the column labelled Sig. (2tailed) Table 3.6 showed a significant difference in the mean scores on the dependent variable for each of the two sets of scores. Because of the value in the Sig. (2tailed) the column is less than .05 (which is .000), there is $a$ significant difference between the two sets of scores. Since the mean scores of students following the treatment $(\mathrm{M}=27.13)$ were more than their mean scores before the treatment $(\mathrm{M}=22.80)$, it was concluded that the students improved in their interpretation scores. The researchers used eta squared to determine the instruction's effect size, as the most commonly used formula: $\mathrm{t} 2 / \mathrm{t} 2+(\mathrm{N}-1)$. As Table 4.9 shows, in this study, $\mathrm{t}=-5.20$. Therefore: $(-5.20)^{2} /(-5.20)^{2}+(15-1)=$ $27.04 / 41.04=0.65$. Therefore, the effect size of .65 is large. That is, intervention in the bilingual group had a large effect on the students' interpretation performance.

During the treatment phase, the researchers worked with the students on the strategies used in subtitling following the guidelines suggested by Pedersen's (2005) strategies, including official translation, specification, substitution and omission. Some samples are presented below based on the strategies extracted from the films worked in the class.

Table 3.7 Bilingual Subtitling: Official equivalent

\begin{tabular}{|c|c|c|}
\hline English Source & Translation & \\
\hline & Pedersen's Strategy & Subtitled Version \\
\hline Something cool & Official Equivalent & 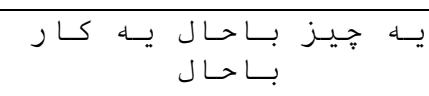 \\
\hline Last year you were only a janitor & Official Equivalent & 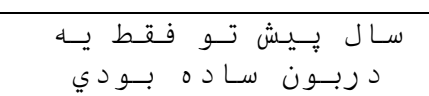 \\
\hline
\end{tabular}


Table 3.8 Bilingual Subtitling: Omission

\begin{tabular}{lll}
\hline English Source & Translation & \\
\hline & Pedersen's Strategy & Subtitled Version \\
\cline { 2 - 3 } If you were the last bitch on earth & Omission & $\ldots$ \\
You filthy & Omission & $\ldots$ \\
\hline
\end{tabular}

\subsection{Interlingual vs Bilingual Subtitling and Interpretation}

The researchers examined the difference between the students' interpretation performance concerning interlingual subtitling and bilingual subtitling using ANCOVA formula to find the third research question's answer. To measure students' scores on interpretation, the current study opted for $\mathrm{Wu}$ (2010) assessment rubrics that are user-friendly and comprehensive, including all aspects required for an interpretation to be regarded as useful in terms of quality. Before, running One-way ANCOVA, the linearity for each group, the homogeneity of regression slopes between the covariate and the dependent variable for every group and the assumption of the equality of variance was checked. First, the general distribution of scores for each of the groups was checked. There appeared to be a linear (straight-line) relationship for each group. Indeed, there has been no indication of a curvilinear relationship.

Moreover, the Sig or probability value for the interaction term (shown above as group*Diff) was .110, safely above the cut-off. There had been no violation of the assumption of homogeneity of regression slopes. Then, the Descriptive Statistics of the two groups were calculated as follows:

Table 3.9 Descriptive statistics for both groups

\begin{tabular}{llll}
\hline \hline Group & Mean & Std. Deviation & $\mathrm{N}$ \\
\hline Interlingual & 27.66 & 4.20 & 15 \\
Bilingual & 27.13 & 2.69 & 15 \\
Total & 27.40 & 3.47 & 30 \\
\hline \hline
\end{tabular}

As shown in Table 3.9, the means score of the interlingual group was 27.66, with the standard deviation of 4.20 , and the mean score of bilingual groups was 27.13 with the standard deviation of 2.69. The number of participants in each group was 15 .

Table 3.10 Test of ANCOVA

\begin{tabular}{|c|c|c|c|c|c|c|}
\hline Source & $\begin{array}{l}\text { Type III } \\
\text { Squares }\end{array}$ & ff & Mean Square & $\mathrm{F}$ & Sig. & Partial Eta Squared \\
\hline$\overline{\text { Corrected Model }}$ & $96.41^{\mathrm{a}}$ & 2 & 48.20 & 5.10 & .013 & .275 \\
\hline Intercept & 55.04 & 1 & 55.04 & 5.83 & .023 & .178 \\
\hline difference & 94.28 & 1 & 94.28 & 9.99 & .004 & .270 \\
\hline group & 2.45 & 1 & 2.45 & .26 & .614 & .010 \\
\hline Error & 254.78 & 27 & 9.43 & & & \\
\hline Total & 22874.00 & 30 & & & & \\
\hline Corrected Total & 351.20 & 29 & & & & \\
\hline
\end{tabular}

a. $\quad$ R Squared $=.275$ (Adjusted R Squared $=.221$ ) 
The results obtained from ANCOVA showed that the groups did not differ significantly. Since the value in this column was more than .05 (here, it was .61); therefore, the result was not significant. There was no significant difference in the students' interpretation scores for subjects in the interlingual and bilingual groups after controlling for scores on the pre-test administered before the intervention.
In the following, two pictures from the films worked with students in the two experimental classes illustrate the comparison between bilingual subtitling and interlingual subtitling.

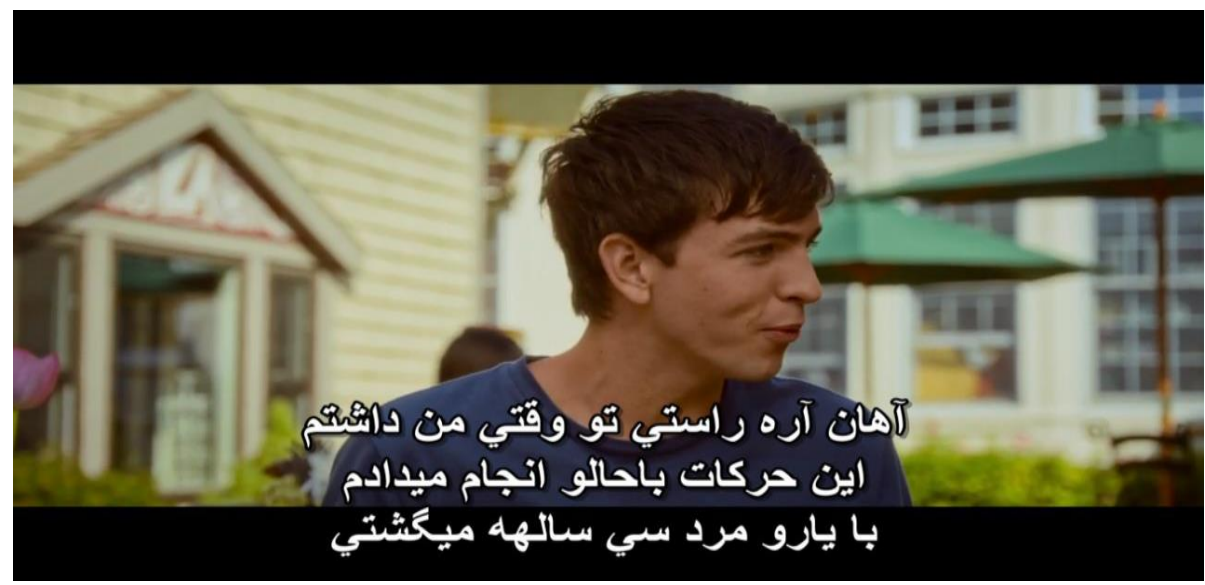

Figure 3.1 Interlingual Subtitling

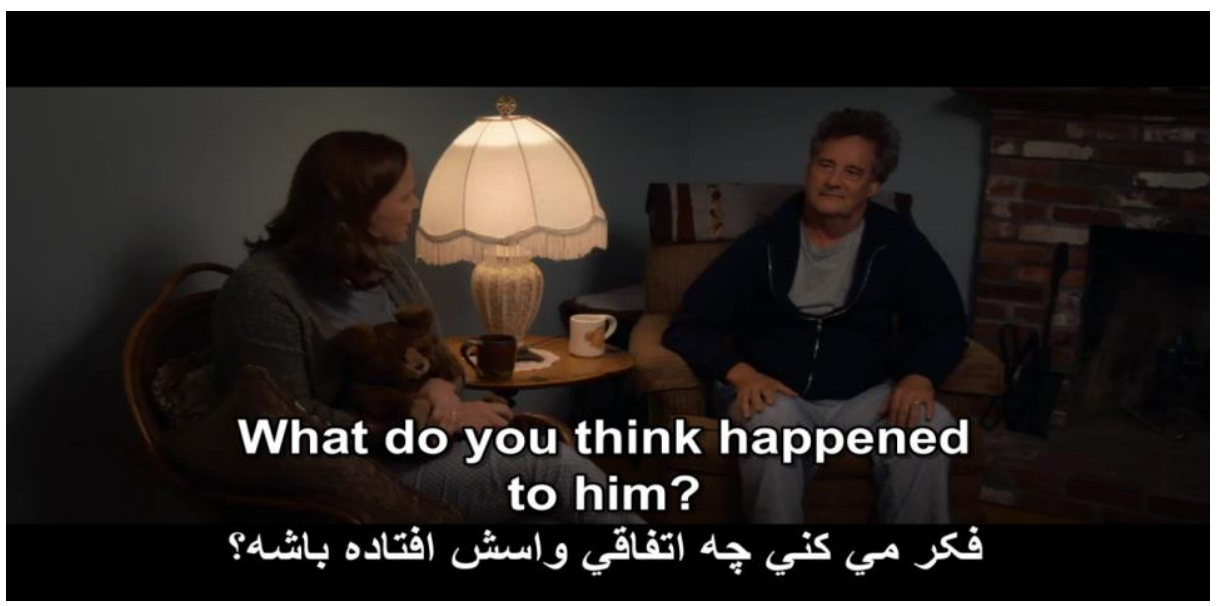

Figure 3.2 Bilingual Subtitling

\subsection{Results Obtained from the Interviews}

As for the last research question of the study regarding the students' thought about audio-visual activity's influence on their interpretation performance, the researchers held interview sessions with four students based on convenience sampling. Two students were selected from the interlingual group, and two students were selected from the bilingual group. To gather the relevant data after the eligible candidates were identified, they were contacted, and the purpose of the study was explained to them. After accepting to participate in the study, the candidates were invited for an in-depth interview using an initially prepared set of open-ended questions for a semi-structured interview. As the participants were asked the predetermined questions, they were free to response as far as they believed necessary. Based on their responses, relevant follow-up questions were asked to probe deeper into the necessary details of the topic of interlingual and bilingual subtitling. The medium of communication in the interview was English. The interview protocol was audio recorded with the participants' permission. The details regarding the venue and timing of the interview meeting were arranged based on the participants' convenience and preferences.

The students in the interlingual group believed that there are some advantages to watching subtitled foreign language programs. First, watching subtitled programs fosters conversational skills. Second, such programs improve interpretation skills. However, these benefits only apply if the subtitles meet the quality requirements. One of the students stated, "The use of Persian language with the spoken version of the words 
had the benefit for us to make the association between the words in both languages simultaneously".

The bilingual group students believed that this type of subtitling's main advantage is that using this kind of subtitles allows them to learn words, expressions, and idioms they do not understand. The translation is automatic and instantaneous (typically to your mother tongue from the second language you are trying to learn). One of the students said that "comparing the two languages simultaneously was a bit difficult at first since we must process the notions in two languages separately in our mind. Sometimes we lagged behind the subtitling, but the point was that seeing the two phrases at the same time helped to make connections between the two languages and to remember the words better."

\section{Discussion}

The present study results revealed that subtitling contributed to improved interpretation performance for undergraduate students learning interpretation courses. As for the first research question of the study concerning the effect of instructing Pedersen's (2005) strategies on BA translation students' oral translation by means of interlingual subtitling, the results showed that interlingual subtitling affects the interpretation performance since the students at this group improved after the treatment phase and the students' scores increased significantly from the mean score of 24.53 to the mean score of 27.66. Moreover, as for the second research question of the study regarding the effect of instructing Pedersen's (2005) strategies on BA translation students' oral translation using bilingual subtitling, the results confirmed that bilingual subtitling affects the interpretation performance since the students at this group improved after the treatment phase and the students' scores increased significantly from the mean score of 22.80 to the mean score of 27.13. However, as for the third research question of the study regarding the significant difference between BA translation students' oral translation through interlingual and bilingual subtitling, the results showed no significant difference between the two groups. The results indeed confirmed that each of these subtitling types had some influence on the students' performance. The effect size of bilingual subtitling was a bit larger than that of interlingual subtitling.

Finally, as for the last research question of the study regarding the students' perspectives of the influence of types of audio-visual activity on their oral translation performance, the results of the interview with the students revealed that all types of translation have specific constraints; no doubt, screen translation is not an exception. What makes subtitling different from other types of translation is that it involves both technical and contextual constraints. Gottlieb (1992) used different terminology and explained that a subtitler is faced with formal (quantitative) and textual (qualitative) constraints. Textual constraints imposed on the subtitles by the film's visual context, whereas formal constraints are the space factors (a maximum of 2 lines and 35 characters) and the time factor.

The study results are in line with the previous study conducted by Sponholz (2003) who concluded that although interlingual subtitles are always perceived as a supplement to a film, they are the most effective audio-visual language transfer mode. The study is also aligned with the previous study carried out by Szarkowska (2005) who confirmed that among audiences there is a growing demand for bilingual subtitling as the authentic materials leading to the better knowledge of foreign languages in general and English language in particular. The present study showed that working on interpretation can be enjoying and challenging while improving interpreting competence. Indeed, subtitling is valuable for the acquisition of foreign languages (Broddason, 2006). Finally, subtitles serve to preserve and revive minority languages, and they are an essential language-learning tool for immigrated groups (O'Connell, 2007). Subtitling can also be used as the assessment tools for evaluating students' interpreting performance. New assessment tools such as computerized dynamic assessment (Modarresi \& Alavi, 2014) can increase the subtitling domain.

The research introduced the applied strategies based on Pedersen's Model (2005) in two subtitling types and determined their subtitling usage. As for the omission strategy, interlingual translators were more inclined to employ this strategy than bilingual strategy. To produce a more favourable translation, interpreters focus on substitution strategy to consider the cultural and social factors that create conditions governing the county's audio-visual media. The study results showed that the students should become aware of these strategies and become competent in interpreting tasks during the courses of interpretation presented to them in their academic studies. Since there is no other similar research work, as far as the researchers know, the present study is not just the same as or even partly identical with any other study in our country. There are some studies dealt with AVTs or translation of cultural words. Akef and Vakili (2010) which considered culture-specific items in the translation of Savushun by Sedighi and Tabrizi (2012) who investigated the effect of norms on audio-visual translations, and Alavi, Karimnia, Salehizadeh (2013) performed a Skoposbased study to investigate the translation of taboos from English into Persian.

The present study also revealed that as interlingual subtitling, the translators could use more such strategies as an omission in their works since the two languages are not presented simultaneously to the viewers. Contemporary translation research focuses on theoretical translation studies and applied translation studies, whereby the causal relationship between translation training and translation students' instructional factors is examined (Holmes, 2004). 
Indeed, according to Holmes (2004), attention to such factors is required "if the discipline is to grow and flourish" (p. 190). The findings of the current research project make a strong case for expanding this focus and embracing the future perspective of students' interpreting performance. As announced by Chesterman (2000), the most potent model of translation is the causal model. The present study concluded that the instructional aspects of interpretation affect interpretation performance.

The widespread use of subtitling in foreign language settings has been prominent in the interpretation courses. Students and learners would like to watch films with subtitles. In our country in which the English language is presented just in a classroom setting and in other countries in which the English language is presented as a second language, learners prefer subtitling to other forms of audio-visual materials. For instance, as concluded by Kurz (1997), a survey of television viewers in the Netherlands revealed that "64\% of adult respondents chose to subtitle overdubbing" (p. 168); giving an even higher survey figure, Kilborn (1991) reports that $82 \%$ of viewers in that country preferred subtitling for foreign language programs. As for the interpretation courses, the results revealed that students' majoring in translation studies are not mostly aware of the translation strategies employed in translation and interpretation performance.

The current study highlighted the role of such strategies, and the researchers of the current study found out that translation instruction has an enormous impact on students' performance on interpretation. Students could learn interpretation strategies based on the most recent translation model specific in interpreting, such as the one employed in this research and work on subtitling and its different types. In this way, they can foster their interpreting knowledge and be critical of the translations provided by the people involved in interpreting tasks and practices.

Official, specification, and substitution strategies were other strategies which their applications were noticeably different in number. The translator was mostly inclined to use substitution for ST items which could be taboo (Cultural). However, due to the reasons mentioned above, registered translators had to follow a range of rules and limitations. The researchers concluded that to achieve a perfect translation work that can fulfil all of the planned objectives, a translator, in addition to linguistic knowledge, should have information about some extra-linguistic matters called socio-linguistic competence. Customs and beliefs are examples of problematic items that a translator should be aware of to present outstanding translation work. If there was a united cultural setting globally and among different languages, the translation act would be much more comfortable enough to replace the source text item with its equivalent in the target text. Nevertheless, some cultural-specific items are unknown in another culture and challenge the translation process.

The difference between interlingual subtitling and bilingual subtitling mainly is due to the limitations issued by governmental policy or in the context of society rooted in cultural and religious norms. Based on which the interlingual subtitling has the chance not to transfer some taboos into Persian. From an instructional perspective, some items were not compatible with cultural, political or governmental ideologies. Translators applied omission strategy to avoid any misperceptions and violate social norms. This type of strategy was used in bilingual subtitling more than interlingual subtitling. However, it is possible that this strategy was used irresponsibly, i.e. without justifying reason is an extreme condition in order to evade any translation crisis points. However, in interlingual subtitling, translators due to comparative linguistics' presentation felt free to transfer most of the items. Of course, another reason for applying omission was the lack of translational competence because some of the translators are not necessarily academically educated.

\section{Conclusion}

What can be concluded is that strategies application procedure was different between interlingual and bilingual versions of the segments worked in the classroom. In interlingual subtitling, mostly the total number of strategies use was different from that of bilingual subtitling. Several obscene phrases and sentences and some culture-specific items were censored in interlingual completely, translated in bilingual subtitling since both languages were presented simultaneously. The translator has no choice but to render the message. The study offers practical implications for translation students and translation teachers. As for the translation teachers, they are mostly recommended to make use of subtitling strategies in the classroom and gain mastery over different types of interpreting strategies and techniques and do not take the interpretation courses as a routine work focusing just on listening and asking students to translate the segments into the Persian language. Translation students should pay attention to the ways that foster their interpreting competence and use audiovisual materials such as subtitling and find the type of subtitling that is more beneficial to them. Research into audio-visual translation is somehow novel concerning the number of related literature found in our country's academic journals and websites so that the translation teachers can act as researchers to conduct more indepth studies in this regard.

\section{References}

Akef, K., \& Vakili, T. (2010). A comparative analysis of culture specific items in two English translations of Savushun. JELS, 2 (4), 157-168. 
Alavi, S. Y., Karimnia, A., \& Salehizadeh, S. (2013). Translation of taboos from English into Persian: A skopos-based study. Elixir Ling. \& Trans, 54, 12289-12292.

As-Safi, A. B. (2001). Lexicalization and modalization of prepositions in English-Arabic translation. International Journal of Arabic-English Studies, 2 (2), 1-17.

Baker, M. (1998). Routledge encyclopedia of translation studies. London: Routledge.

Broddason, T. (2006). The Instructional Value of Subtitles. Informal learning and digital media: constructions, contexts, consequences.: University of Southern Denmark, 21-23.

Chesterman, A. (2000). A causal model for translation studies. In O. Maeve (Ed.), Intercultural Faultines (15-27). Manchester: St. Jerome Publishing.

Cohen, J. (1992). Quantitative methods in psychology. Psychological Bulletins, 112 (1), 155-159.

Darwish, A. (2003). The Transfer Factor: Selected essays on translation and cross-cultural communication. Australia: Writescope Publishers.

Davies, M. G. (2004). Multiple voices in the translation classroom: Activities, tasks and projects. Amsterdam, the Netherlands: John Benjamins Publishing Company.

Gambier, Y. (2003). Screen transadaptation: Perception and reception. The Translator, 9 (2), 171-189.

Gile, D. (1995). Basic concepts and models for interpreter and translator training. Amsterdam \& Philadelphia: John Benjamins.

Gottlieb, H. (1992). Subtitling-a new university discipline. In C. Dollerup \& A. Loddegaard (Eds.), Teaching translation and interpreting: Training, talent and experience (pp. 161-170). Amsterdam: John Benjamins Publishing Company.

Gottlieb, H. (1998). Subtitling. In M. Baker (ed.), Routledge encyclopedia of translation studies (pp. 261-274). London-New York: Routledge.

Holmes, J. S. (2004). The name and nature of translation studies. In L. Venuti (ed.), The translation studies reader (pp. 180-92). Oxford: OUP.

Hulme, C. (2000). Language processing mechanisms and immediate memory: Possible implications for simultaneous interpreting. ASCONA: Complex Cognitive Processes.

Jalilzadeh, K., Modarresi, Gh., \& Rohani, H. (2020). A Comparative study of instruction types and reading comprehension for young learners. In $\mathrm{H}$. H. Uysal, Political, pedagogical and research insight into early language education (123-132). UK: Cambridge Publishing Press.

Karamintroglou, F. (1999). A proposed set of subtitling standards in Europe. Translation Journal, 2 (2), 12-26.

Khakshour Forutan, M., \& Modarresi, Gh. (2018). Translation of cultural taboos in Hollywood movies in professional dubbing and nonprofessional subtitling. Journal of Intercultural Communication Research, 47(6), 454-473.

Khoramy, F., \& Modarresi, Gh. (2019). A Rasch-based validation of the evaluation rubric for consecutive interpreting performance. Sendebar, $30,221-244$.

Kilborn, K. (1991). Selective impairment of grammatical morphology due to induced stress in normal listeners: Implications for aphasia. Brain and Language, 41(2), 275-288.

Kutz, W. (1994). Interpreter training according to a competency model. In H. Breitung (Ed.), Interpreter and translator training (pp. 89-96). USA: UW-SP Foundation Press.

Luyken, G. M., Herbst, T., Langham-Brown, J., Reid, H. \& Spinhof, H. (1991). Overcoming language barriers in television. Manchester: The European Institute for the Media.

McCoy, C. (2016). Good kids. Los Angeles: Voltage Pictures.

Mendez, F. Z. (2001). The shortened Spanish version of the personal report of confidence as speaker: Reliability and validity in adolescent population. Behavioral Psychology, 12 (1), 25-42.

Mizuno A. (2005). Process model for simultaneous interpreting and working memory. Meta, 50 (2), 739-752.

Modarresi, Gh. (2019). Developing and validating involvement in translation scale and its relationship with translation ability. Forum: International Journal of Interpretation and Translation, 17(2), 225-248.

Modarresi, Gh., \& Alavi, S. M. (2014). Designing and validating a test battery of computerized dynamic assessment of grammar. TELL, 14 (2), $1-29$.

O’Connell, E. (2007). Screen Translation. In P. Kuhiwczak \& K. Littau (Eds.), A companion to translation studies (pp.120-133). Toronto: Multilingual Matters Ltd.

Osaka, M. (2002): Nou no memo-cho: wakingu memori (Working memory: The sketchpad in the brain). Tokyo: Shinyosha. 
Pedersen, J. (2005). How is culture rendered in subtitles. Challenges of multidimensional translation: Conference proceedings, 32, 1-18.

Sedighi, A., \& Tabrizi, S. N. (2012). On audio-visual translation: The effect of norms of dubbing taboos into Persian movies after the Islamic revolution in Iran. Journal of Language and Translation, 3 (1), 37-49.

Sponholz, C. (2003). Teaching audio-visual translation theoretical aspects, market requirements, university training and curriculum development. Unpublished thesis, Retrieved October 12, 2008, Retrieved from http://isg.urv.es/library/papers/thesis_Christine Sponholz.doc

Szarkowska, A. (2005). The power of film translation. Translation Journal, 3(3). Retrieved October 2016 from: http://accurapid.com/journal/09av.htm.

Wu, S. C. (2010). Assessing simultaneous interpreting: A study on test reliability and examiners assessment behavior (Unpublished $\mathrm{PhD}$ thesis). The School of Modern Languages, Newcastle University. 